\title{
Outcome of post caesarean pregnancy in a tertiary care centre in south India
}

\author{
Sathya Prabha, Manasi Naralkar, Prema \\ Corresponding author: Dr Sathya Prabha, Assistant Professor, Department of Obstetrics and \\ Gynaecology, Karpagam Faculty of Medical Sciences and Research, Coimbatore, Tamilnadu, \\ India; Email - sathyapraba.mdu@gmail.com
}

Distributed under Attribution-Non Commercial - Share Alike 4.0 International (CC BY-NC-SA 4.0)

\begin{abstract}
Objectives: The objective is to estimate the success rate, safety and efficacy of VBAC (vaginal birth after cesarean section) by comparing the maternal and perinatal outcome with the elective repeat cesarean section (ERCS). Methodology: This was a prospective, cohort study done over a period of twelve months in a tertiary care centre. Based on the patients' preference, a total of 211 women who satisfied the inclusion criteria were divided into two groups - either a trial of labour after cesarean section (TOLAC) or ERCS group. Results: Success rate of VBAC was found to be $47.9 \%$. About $15 \%$ of failed VBAC was due to the tendency to abandon a TOLAC midway. Although the maternal complications were found to be higher in TOLAC, p value (0.347) was not found to be significant. There was no increased risk of neonatal morbidity and mortality in the TOLAC group when compared to ERCS ( $p=0.814)$. There was also no difference found in APGAR scores $(<7)$ at 5 minutes and NICU admissions in the TOLAC group and in ERCS group $(\mathrm{p}=0.899)$. Conclusion: The success rate of VBAC was found to be $47.9 \%$. There was no significant risk of maternal and perinatal complications compared to ERCS.
\end{abstract}

Keywords: Elective repeat caesarean section, maternal and neonatal outcome, trial of labour after caesarean section.

Mode of delivery following a previous cesarean section is of major concern today. Due to the rising cesarean section rate and its associated complications, we need to pause and think of methods to improve normal labour, especially in a low resource country like India with many small health care providers who might not be able to strictly adhere to the guidelines. Although VBAC was proven to be successful in developed countries we need more studies in our Indian set up with the local population to improve the quality of health care and create awareness among patients. The cesarean rate has risen from $21 \%$ in 1996 to $32.9 \%$ in $2009^{1,2}$. The 2010 National Institutes of Health consensus conference on VBAC highlighted high-grade evidence that maternal mortality risk is decreased by VBAC compared with a repeat cesarean $(3.8$ vs 13.4 of 100,000$)^{2}$. Data suggest decreasing the primary cesarean delivery rate and increasing the VBAC rate as key strategies to decrease the cesarean rate ${ }^{3}$. In pregnancies complicated by a history of previous cesarean section, both a TOLAC and ERCS are safe options for delivery with overall low absolute rates of adverse maternal or fetal outcomes. Although a repeat cesarean section is associated with increased maternal risks, most of these risks can be anticipated. In comparison, the success of a TOLAC is unpredictable. If a VBAC is achieved, it confers lowest risks

Received: $18^{\text {th }}$ March 2020. Accepted: $4^{\text {th }}$ May 2020.

Prabha S, Naralkar M, Prema. Outcome of post cesarean pregnancy in a tertiary care centre in south India. The New Indian Journal of OBGYN. 2020; 7(1): 31-5. 
to both the mother and the infant, but, if the TOLAC fails, there is a greater risk to both ${ }^{4}$. So to reduce the overall morbidity and to improve the success rate of TOLAC patient selection should be done with utmost care. Potential risk and benefits of both TOLAC and elective repeat cesarean delivery should be discussed with the patient and documented. Discussion should consider individual characteristics that affect the likelihood of complications associated with TOLAC and ERCS so that a woman can choose her intended route of delivery ${ }^{5}$. VBAC offers the advantage of avoiding major abdominal surgery and have lower rates of hemorrhage, thrombo embolism, and infection, and a shorter recovery period than women who have an elective repeat cesarean delivery ${ }^{6}$. Additionally, for those considering future pregnancies, VBAC may decrease the risk of maternal consequences related to multiple cesarean deliveries (eg, hysterectomy, bowel or bladder injury, transfusion, infection, and abnormal placentation such as placenta previa and placenta accreta) ${ }^{7-9}$. Although there is no universally agreed upon discriminatory point, evidence suggests that women with at least a $60-70 \%$ likelihood of achieving a VBAC who attempt TOLAC experience the same or less maternal morbidity than women who have an elective repeat cesarean delivery ${ }^{10,11}$. These are the scientific proven reasons why we look forward to give more number of successful TOLAC in our settings and encouraging the same in other tertiary care centres in India.

\section{Materials and methods}

This is a prospective, cohort study carried out in the labour theatre, of tertiary care hospital for a period of twelve months from October 2015 to October 2016. All the patients with previous cesarean section admitted in our hospital for safe confinement was chosen. Among this group, patients who gave consent for the study and satisfied the inclusion criteria were selected as the study sample.

Women with previous one lower transverse cesarean section, singleton fetus in cephalic presentation with clinically adequate pelvis were included in the study. Women with more than one cesarean section, classical cesarean scar, previous myomectomy, malpresentation and interdelivery interval less than 2 years were excluded.

VBAC counseling was given after confirming the patients' eligibility for TOLAC. Eligible women were given an information sheet during pregnancy and written and informed consent was obtained. This study was a patient preference study. Women were allocated their preference for either a TOLAC or ERCS. We have included a total of 211 women in our study. Detailed history was taken and patients who preferred ERCS were taken up for elective cesarean section after completion of 39 weeks. In patients who preferred TOLAC, we waited for spontaneous onset of labour. Induction after 39 completed weeks was done as per our hospital protocol in women who did not go into spontaneous labour. In some patients induction of labour was considered prior to 37 weeks in the presence of other risk factors. Method of induction was chosen according to Bishop score. All women were closely monitored in labour with one to one nursing care. Women who chose to abandon trial of labour halfway were taken up for emergency cesarean section in view of maternal request. The percentage of this group of patients who contribute to the failed TOLAC were also studied. Continuous electronic fetal monitoring was done in active labour. Any maternal or fetal abnormalities were identified and promptly acted on. Emergency cesarean section was done when necessary. Records were kept about maternal and perinatal complications in labour and after delivery during the period of hospital stay.

The SPSS 18.0 software package was utilized to analyze the data. All values were expressed as mean and standard deviation. We used the chi-square test to calculate the significance of the association between groups.

\section{Results}

Out of 211 patients, $119(56.4 \%)$ were willing for VBAC and had undergone trial of labour and 92 (43.6\%) were taken up for elective cesarean section in view of maternal request. Among the 119 number of patients, 57 had a successful VBAC (47.9\%) and 62 had an emergency LSCS.

Although maternal complications of uterine rupture, post operative infection and scar dehiscence were found to be high in the trial of labour group, $p$ value $(0.347)$ is not found to be significant (figure 1). Respiratory distress was found in

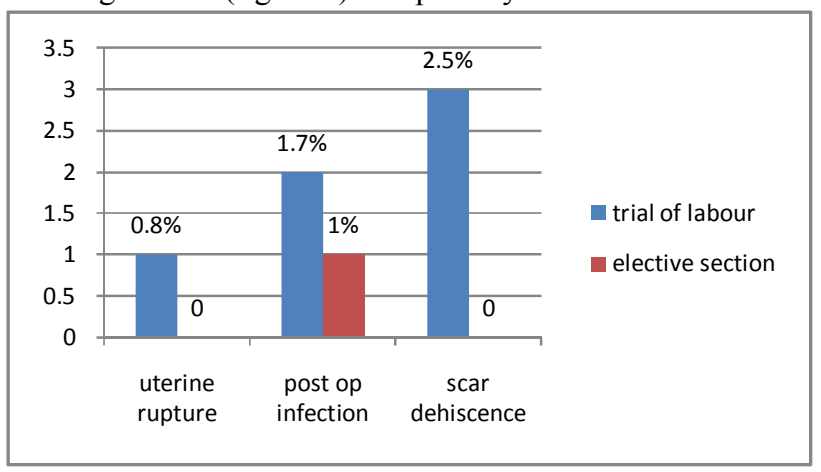

Figure 1: Maternal complications 
6 neonates (5\%) in the TOLAC group and 4 neonates $(4.3 \%)$ in ERCS group (figure 2). There was no case of neonatal

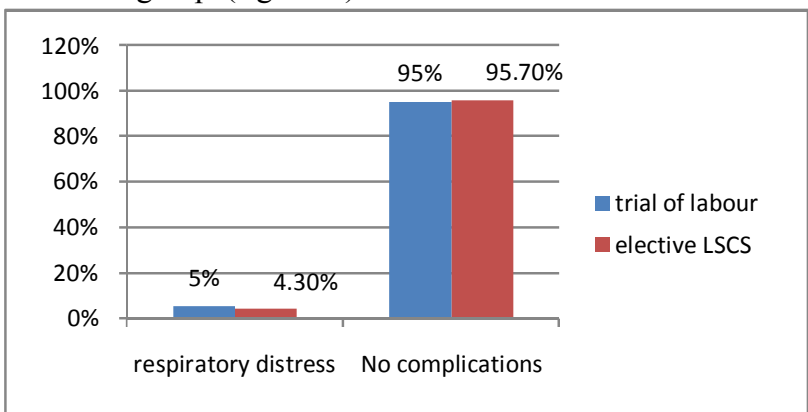

Figure 2: Perinatal complications in the TOLAC compared to the ERCS group.

HIE, transient tachypnoea of newborn, birth trauma or any other serious neonatal morbidity and mortality seen in the study group. $\mathrm{P}$ value is not found to be significant $(\mathrm{p}=0.814)$. In the trial of labour group among 119 patients 6 neonates $(5 \%)$ are found to have an APGAR score $<7$ at the end of 5minutes (figure 3). In ERCS, 5 neonates (5.4\%) are found

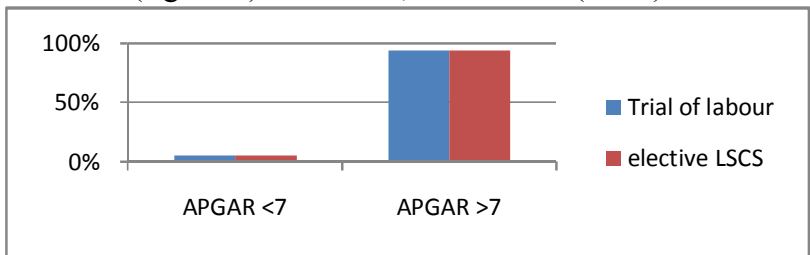

Figure 3: APGAR scores at the end of 5 minutes in the trial of labour group was compared to the elective cesarean group.

to have an APGAR score $<7$ at the end of 5 minutes. P value is not found to be significant $(\mathrm{p}=0.899)$. In the TOLAC group there was 12 NICU admissions (10.1\%) and in ERCS group there was $9 \mathrm{NICU}$ admissions (9\%) including preterm care (figure 4). $\mathrm{P}$ value is not found to be significant $(\mathrm{p}=0.899)$.

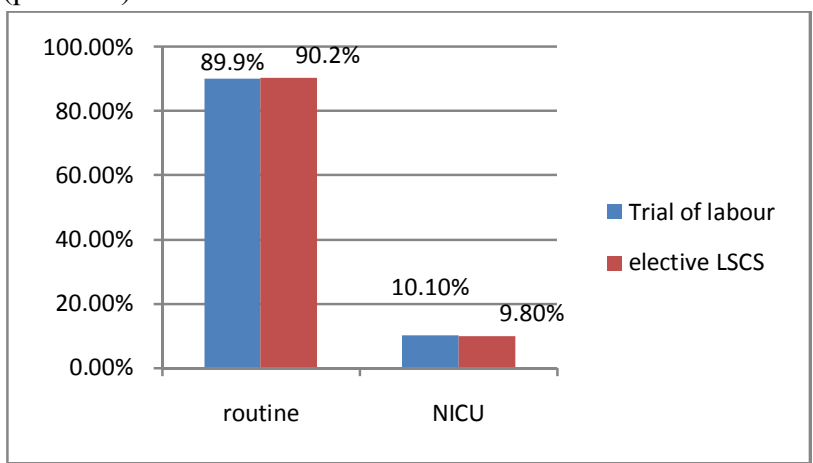

Figure 4: NICU admissions in TOLAC group and in ERCS group

\section{Discussion}

In our study $43.6 \%$ of the patients underwent TOLAC and the success rate of VBAC was found to be $47.9 \%$. Analysing the maternal outcomes in the study group no significant maternal morbidities of uterine rupture, post operative infection or scar dehiscence noted $(p=0.347)$. There was no significant respiratory distress, neonatal HIE, transient tachypnoea of newborn, birth trauma or any other serious neonatal morbidity and mortality seen in the study group ( $\mathrm{p}=0.814$ ). There was also no significant difference in apgar scores and NICU admissions between both the groups.

In a study by Landon et $\mathrm{al}^{12}$, Stone and associates ${ }^{13}$, successful rates of VBAC between $56 \%$ and $80 \%$ are reported. ACOG $2019^{5}$ reported that generally, 60 to 80 percent of TOLAC result in vaginal delivery. In a metaanalysis done in sub-Saharan Africa involving 14 studies $^{14}$, the success of vaginal birth after cesarean section was $69 \%$. The success rate of VBAC was $47.9 \%$ in the study group.

In a meta-analysis, a TOL at term was associated with a maternal mortality of 1.9 per 100,000 versus 9.6 per 100,000 for a repeat $\mathrm{CD}$ (relative risk [RR], 0.27$)^{16}$. In a study by Landon and colleagues $2004^{12}$, the percentage of uterine rupture, uterine scar dehiscence and uterine infection was $0.7 \%, \quad 0.7 \%$ and $2.9 \%$ respectively. To the contrary, however, there were no uterine ruptures, $0.5 \%$ uterine scar dehiscence and $1.8 \%$ uterine infection in the ERCS group. The risk of uterine rupture was higher among women undergoing a TOLAC, but the absolute risk was small only 7 per 1000. On meta-analysis, the rate of uterine rupture for all women with a history of 1 previous cesarean section is $0.3 \%$, and the rate of uterine rupture is significantly higher for women who undergo a TOLAC compared with a ERCS $(0.47 \% \text { vs } 0.026 \% ; \mathrm{p}<.001)^{15}$. Most of the high-quality studies on uterine rupture are not stratified by spontaneous versus induced labor, thereby limiting the conclusions that can be made from their results ${ }^{15}$. In our study group there was 1 case $(0.8 \%)$ of uterine rupture, 3 cases $(2.5 \%)$ of uterine scar dehiscence, 2 cases $(1.7 \%)$ of post operative infection. In the ERCS group, there was 1 case $(1.1 \%)$ of post operative infection with no uterine rupture or scar dehiscence. Although maternal complications of uterine rupture, post operative infection and scar dehiscence were found to be high in TOLAC, $p$ value $(0.347)$ is not found to be significant. There was no maternal death or other serious maternal complications in the study group.

The perinatal mortality for TOLAC is 1.3 deaths per 1000 deliveries, and 0.5 deaths per 1000 deliveries for 
women undergoing a repeat $\mathrm{CD}$ for an RR of $1.82(95 \% \mathrm{CI}$, 1.24-2.76; $p$ 5.041). The incidence of HIE was higher in both low-risk ( $0.89 \%$ for TOL vs $0.32 \%$ for repeat CD) and highrisk $(1.29 \%$ for TOL vs $0.20 \%$ for repeat $\mathrm{CD})$ pregnancies, but the significance of this difference was not assessed ${ }^{15}$. In the same study the need for bag-and-mask ventilation for neonatal respiratory distress was found to be significantly higher following a TOL $(5.4 \% ; 95 \%$ CI, 3.5\%-7.6\%) than a ERCS $(2.5 \% ; 95 \%$ CI, $0.72 \%-5.0 \%)$. Differences in neonatal intubation rates also could not be assessed ${ }^{15}$. Landon and colleagues (2004) $)^{12}$, found that rates of stillbirth $(0.08 \%)$ and hypoxic ischemic encephalopathy $(0.08 \%)$ were significantly greater in the trial of labour. In the present study respiratory distress was $5 \%$ in the trial of labour group and $4.3 \%$ in ERCS group. There was no case of neonatal HIE, transient tachypnoea of newborn, birth trauma or any other serious neonatal morbidity and mortality seen in the study group. Chi square value for the association between neonatal morbidity and mortality in TOLAC and in ERCS group is not found to be significant ( $\mathrm{p}=0.814$ ). Apgar scores, although not always predictive of HIE, can often be used to identify at-risk infants. In a study by Fisler et al and Kamath et al, apgar scores were not consistently different in infants delivered by a TOLAC versus ERCS ${ }^{16,}{ }^{17}$. Flamm BL and associates ${ }^{18}$ found no significant differences in five-minute apgar scores or neonatal intensive care unit admissions when infants delivered by TOLAC are compared with those delivered by ERCS. In the trial of labour group 5\% were found to have an apgar score $<7$ at the end of 5 minutes. In ERCS group 5 neonates $5.4 \%$ were found to have an apgar score $<7$ at the end of 5 minutes. $\mathrm{P}$ value is not found to be significant $(\mathrm{p}=0.899)$. When assessing the relationship between method of delivery and neonatal admission to the intensive care unit (ICU), most trials found no difference between TOLAC and ERCS ${ }^{15}$. In the trial of labour group there was $10.1 \%$ NICU admissions and in elective lower segment cesarean section group there was $9 \%$ NICU admissions including preterm care. Based on NICU admissions, chi square value (0.005) for the comparison of neonatal risk in TOLAC and in ERCS is not found to be significant $(\mathrm{p}=0.899)$.

Limitations - It is a short term study, therefore long term complications of ERCS such as bowel and bladder adhesions, future pregnancy complications could not be studied.

\section{Conclusion}

The success rate of VBAC was found to be $47.9 \%$ in the study sample. This difference might be due to change in characteristics of obstetric population, acceptance and perseverance of the women to undergo TOLAC and their mental strength to withstand labour. It also depends upon the hospital resources, expertise and availability of the obstetrician, as well as the counseling and support to the patient throughout pregnancy and labour. There is no statistically significant risk of maternal and perinatal complications. This might be due to early intervention and delivery. Hence VBAC is found to be safe with no significant risk of maternal and perinatal complications when done in a tertiary care centre following hospital guidelines.

\section{Conflict of interest: None. Disclaimer: Nil.}

\section{References}

1. National Institutes of Health Consensus Development Conference Panel. National Institutes of Health Consensus Development conference statement: vaginal birth after cesarean: new insights March 8-10, 2010. Obstet Gynecol. 2010; 115(6): 1279-95.

2. Hamilton B, Martin J, Ventura S. Births: Preliminary Data for 2009. National Statistics Reports. Vol 59. Hyattsville, MD: National Center for Health Statistics; 2010.

3. Zhang J, Troendle J, Reddy U, Laughon K, Branch W, Burkman R, et al. Contemporary cesarean delivery practice in the United States. Am J Obstet Gynecol. 2010; 203(4): 326.e1-326.e10.

4. Sargent J, Caughey AB. Vaginal Birth After Cesarean Trends: Which Way Is the Pendulum swinging? Obstet Gynecol Clin North Am. 2017 Dec; 44(4): 655-66.

5. ACOG Practice Bulletin No. 205. Vaginal Birth After Cesarean Delivery. Obstet Gynecol. 2019 Feb;133(2): e110-e127.

6. Curtin SC, Gregory KD, Korst LM, Uddin SF. Maternal morbidity for vaginal and cesarean deliveries, according to previous cesarean history: new data from the birth certificate, 2013. Natl Vital Stat Rep. 2015; 64(4): 1-13.

7. Silver RM, Landon MB, Rouse DJ, Leveno KJ, Spong $\mathrm{CY}$, Thom EA, et al. Maternal morbidity associated with multiple repeat cesarean deliveries. Obstet Gynecol. 2006;107:1226-32.

8. Ananth CV, Smulian JC, Vintzileos AM. The association of placenta previa with history of cesarean 
delivery and abortion: a meta analysis. Am J Obstet Gynecol.1997;177: 1071-8.

9. Nisenblat V, Barak S, Griness OB, Degani S, Ohel G, Gonen R. Maternal complications associated with multiple cesarean deliveries. Obstet Gynecol. 2006; 108: 21-6.

10. Cahill AG, Stamilio DM, Odibo AO, Peipert JF, Ratcliffe SJ, Stevens EJ, et al. Is vaginal birth after cesarean (VBAC) or elective repeat cesarean safer in women with a prior vaginal delivery? Am J Obstet Gynecol. 2006; 195: 1143-7.

11. Grobman WA, Lai Y, Landon MB, Spong CY, Leveno $\mathrm{KJ}$, Rouse DJ, et al. Can a prediction model for vaginal birth after cesarean also predict the probability of morbidity related to a trial of labor? Am J Obstet Gynecol. 2009; 200: 56.e1-6.

12. Landon MB, Hauth JC, Leveno KJ, Spong CY, Leindecker S, Varner W, et al. Maternal and perinatal outcomes associated with trial of labour after prior caesarean delivery. NEJM. 2004; 351: 2581-9.

13. Stone C, Halliday J, Lumley J, Brennecke S. Vaginal birth after caesarean (VBAC): a population study. Paediatr Perinat Epidemiol. 2000; 14: 340-8.

14. Boulvain M, Fraser WD, Brisson-Carroll G, Faron G, Wollast E. Trial of labour after caesarean section in subSaharan Africa: a meta-analysis. British Journal of Obstetrics and Gynaecology. 1997;104: 1385-90.
15. Guise JM, Eden K, Emeis C, Denman M, Marshall N, Fu R, et al. Vaginal birth after cesarean: new insights. Evidence report/technology assessment no.191. AHRQ Publication No. 10-E003. Rockville (MD): Agency for Healthcare Research and Quality; 2010.

16. Fisler RE, Cohen AC, Ringer SA, Lieberman E. Neonatal outcome after trial of labor compared with elective repeat cesarean section. Birth. 2003; 30(2): 83-8.

17. Kamath BD, Todd JK, Glazner JE, Lezotte D, Lynch AM. Neonatal outcomes after elective cesarean delivery. ObstetGynecol. 2009; 133(6):1231-8.

18. Flamm BL, Geiger AM. Vaginal birth after caesarean delivery: an admission scoring system. Obstet Gynecol. 1997; 90: 907.

Sathya Prabha ${ }^{1}$, Manasi Naralkar ${ }^{2}$, Prema $^{3}$

${ }^{1}$ Assistant Professor, Department of Obstetrics and Gynaecology, Karpagam Faculty of Medical Sciences and Research, Coimbatore, Tamilnadu; ${ }^{2}$ Consultant, Dr.Patankar Hospital Pvt Ltd 500/B/1, Parvathi, Opposite Sarasbaug, Pune, Maharashtra; ${ }^{3}$ Associate Professor, Department of Obstetrics and Gynaecology, Karpagam Faculty of Medical Sciences and Research, Coimbatore, Tamilnadu, India. 